\title{
Tartary Buckwheat Extracts Regulate Insulin Sensitivity through IKK//IR/IRS-1/Akt Pathway under Inflammation Condition in Mice
}

\author{
Hanying Tian ${ }^{1}$, Wenjun Zhao ${ }^{2}$, Xudan Guo ${ }^{3}$, Baolin Liu ${ }^{2}$, Min Wang ${ }^{1, *}$ \\ ${ }^{1}$ College of Food Science and Engineering, Northwest A \& F University, YangLing, Shaanxi, China \\ ${ }^{2}$ Department of Pharmacology of Chinese Materia Medica, China Pharmaceutical University, Longmian Road, Nanjing, China \\ ${ }^{3}$ Chinese Cereals and Oils association, Baiwanzhuang Street, Xicheng District, Beijing, China \\ *Corresponding author: wangmin20050606@163.com
}

Received April 24, 2014; Revised June 05, 2014; Accepted June 18, 2014

\begin{abstract}
Tartary buckwheat is rich in flavonoids which have positive effects on preventing chronic disease. But the mechanism of tartary buckwheat ameliorating chronic disease is still poorly understood. This study investigated the regulation of insulin action in skeletal muscle by tartary buckwheat extracts (TBE) under inflammation states in mice. In mice with insulin resistance, glucose intolerance and insulin intolerance was reversed and muscular and hepatic glycogen levels were significantly increased by oral administration of TBE. Furthermore, TBE inhibited inflammation-stimulated IKK $\beta$ activation and IRS-1 serine phosphorylation in skeletal muscle tissue, and effectively facilitated IRS-1 tyrosine and downstream molecule Akt phosphorylation, leading to an increase in insulin-mediated glucose uptake in skeletal muscle tissue. The results showed that TBE modulated positively the phosphorylation of IRS-1 function in inflammatory condition to regulation the insulin sensitivity.
\end{abstract}

Keywords: tartary buckwheat extracts, insulin, inflammation, mice, signal pathway

Cite This Article: Hanying Tian, Wenjun Zhao, Xudan Guo, Baolin Liu, and Min Wang, "Tartary Buckwheat Extracts Regulate Insulin Sensitivity through IKK $\beta /$ IR/IRS-1/Akt Pathway under Inflammation Condition in Mice.” Journal of Food and Nutrition Research, vol. 2, no. 6 (2014): 321-329. doi: 10.12691/jfnr-2-6-9.

\section{Introduction}

Epidemiology has indicated that inflammation is tightly linked with obesity and insulin resistance. Insulin resistance is the fundamental of metabolic syndrome and characterized by specific impairment of insulin phosphatidylinositol 3-kinase (PI3K) signaling, which is attributed to inflammatory molecules [1,2]. Generally, inflammatory cytokines induce insulin resistance via attenuating tyrosine phosphorylation of insulin receptor substrate-1(IRS-1), then inhibiting the downstream PI3K signal transduction [3]. Under inflammation condition, pro-inflammatory cytokines can activate intermediary inflammatory signaling pathways, such as IKK $\beta / \mathrm{NF}-\kappa \mathrm{B}$ pathway, which reduces insulin sensitivity with misleading serine phosphorylation of IRS-1 instead of tyrosine phosphorylation directly or indirectly in the insulin signaling pathway [4]. In IKK $\beta / N F-\kappa B$ pathway, I $\kappa$ Binase $\beta(\operatorname{IKK} \beta)$ is a proximal upstream activator of nuclear factor-kappa B (NF- $\mathrm{B})$, which aggravates insulin resistance through activating $\mathrm{NF}-\kappa \mathrm{B}$ transcription [5]. Accumulated evidence has established that IKK $\beta / \mathrm{NF}-\kappa \mathrm{B}$ also results in the production proinflammatory cytokines through a feedback regulation mechanism [4]. And this is also confirmed from genetics, that the mice in muscle deficient of IKK $\beta$ gene is inhibited the $\mathrm{I} \kappa \mathrm{B} / \mathrm{NF}-\kappa \mathrm{B}$ pathway, improved insulin sensitivity [6]. Therefore, the main way to relief the insulin resistance is to control the pro-inflammatory cytokines production or inhibition the inflammatory kinase activity. At present, mounting evidence indicates that flavonoids can availably ameliorate inflammation and insulin resistance $[7,8]$.

Tartary buckwheat (Fagopyrum tartaricum Gaertn.) which is a pseudocereal belongs to the Polygonaceae family and is mainly grown in mountainous regions $[9,10]$. There are affluent flavonoids in tartary buckwheat than common buckwheat and general cereals [11,12]. Meanwhile, studies have showed that flavonoids possess strongly antioxidant ability to scavenge oxygen radicals in vivo and in vitro, based on their structure [13]. Accumulating investigations have revealed that flavonoids have positive effects on the regulation of glucose homeostasis and anti-inflammatory functions alleviating insulin-mediated chronic diseases, such as insulin resistance [14]. Similarly, tartary buckwheat is concerned on the antioxidant activity due to the high level of flavonoids. Therefore, there is now much interested in tatary buckwheat for its function of improving chronic disease and inflammation. In addition, previous researchers have found that the antioxidant ability of tartary buckwheat is significant linear correlation with the content rutin and total flavonoids [11,15]. Lee et al. [16] also demonstrated that rutin could ameliorate hyperglycemia and hyperinsulinemia in fructose-rich diet- 
induced mice. Gong and colleagues [17] and Lee and colleagues [18] found that flavonoids from tatary buckwheat possessed hypoglycemic effect and prevented liver inflammation injury and oxidative stress in mice. But there is little reference on tartary buckwheat extracts regulation the molecular or signal transduction mechanism of inflammatory. In the present study, we investigated the effect of tartary buckwheat extracts (TBE) on the regulation of insulin sensitivity in insulin-resistant conditions in mice and the underlying target molecular of regulation insulin action in IKK $\beta /$ IRS-1/Akt-dependent pathway.

\section{Materials and Methods}

\subsection{Materials}

\subsubsection{Preparation of Tartary Buckwheat Extracts (TBE)}

Tartary buckwheat extracts (TBE) were extracted from Chuanqiao \#1. Briefly, TBE were extracted twice with 20 volumes (v/w) of absolute methanol. After vacuumconcentrated, the methanol extracts were removed lipids with petroleum benzene $(20 \mathrm{~mL})$ over night, then freezedried to obtain powder in which the contents of flavonoids and rutin were respectively $27.51 \%$ and $12.90 \%$ detected by spectrophotometer (UVmini-1240, shimadzu, Tokyo Japan) and HPLC (Waters, U.S.A). The TBE was stored at $4{ }^{\circ} \mathrm{C}$ before use.

\subsubsection{Regents}

Tartary buckwheat (Chuanqiao \#1) was provided by Xichang HangFei Bitter Buckwheat Exploitation Center (China). Metformin (Met) was from Sino-American Shanghai Squibb Pharma and dissolved in normal saline (NS). For animal experiments, the TBE and metformin were dissolved in normal saline. Lipopolysaccharide (E.coil serotype055:B5, LPS) and insulin were obtained from Sigma (St. Louis, MO, USA). The commercial kits for oral glucose tolerance test (OGTT), insulin tolerance test (ITT), glycogen content were purchased from Nanjing Jiancheng Bioengineering Institute (Jiangsu, China). Antiphospho-IRS-1(Ser307) (BS4104), anti-IRS-1(R301) (BS1408), anti-phospho-Akt (T308) (BS4008), anti-Akt (A444) (BS1810), anti-phospho-IKK $\beta$ (Y199) (BS 4320), and anti-IKK $\beta$ (F182) (BS1407) were obtained from Bioworld Technology (MN, USA), and anti-phosphoTyr(PY99) (sc-7020) from Santa Cruz biotechnology, Inc. (CA, USA).

\subsubsection{Animals}

ICR male mice (6-8 weeks of age), supplied by the Laboratory Animal Center of Nanjing Qinglongshan, were used throughout experiments. The animal care and treatment were maintained in conformity with the Provisions and General Recommendation of Chinese Experimental Animals Administration Legislation.

\subsubsection{Preparation of Macrophages-Derived Conditioned Medium}

Peritoneal macrophages were prepared as described previously [19]. Mice were killed by cervical dislocation, and injected intraperitoneally of $5 \mathrm{ml}$ of PBS. Two minutes after of gentle abdominal massage, PBS containing peritoneal macrophages was collected, and then incubated in six-well plates at a cell density of $2 \times 10^{6} /$ well for $4 \mathrm{~h}$. And then nonadherent cells were removed and adherent cells were washed twice with PBS, and incubated sequentially for $24 \mathrm{~h}$ in serum-free DMEM with or without LPS $(5 \mu \mathrm{g} / \mathrm{ml})$. Then, the culture medium with macrophages were centrifuged and the supernatant contained high levels of TNF- $\alpha$ and IL-6 (Interleukin 6) was collected as macrophages-derived conditioned medium (Mac-CM). The Mac-CM was stored at $-70{ }^{\circ} \mathrm{C}$ before use.

\subsection{Methods}

\subsubsection{Oral Glucose Tolerance Test (OGTT) in Mice}

After12 h of food deprivation, mice (10 mice per group) were treated by oral gavage with either vehicle (normal saline), or TBE (100, 200 and $500 \mathrm{mg} / \mathrm{kg}$ ), or metformin (200 mg/kg). After $30 \mathrm{~min}$, the mice were intraperitoneally injected with or without MacrophageCM (0.1 ml/10g, diluted with normal saline, 1:1, v/v, i.p.). Then, mice were orally administered with glucose solution (2 g/kg, p.o.) for another $30 \mathrm{~min}$. Blood was collected from orbital sinus at $0,30,60$ and 120 min after glucoseload, and levels of blood glucose were determined with a commercial kit based on glucose oxidase peroxidase (GOD-POD) method and blood glucose Area under curve (AUC-G) was calculated as follows: $0.5 \times[\mathrm{Bg} 0+\mathrm{Bg} 30] / 2$ $+0.5 \times[\mathrm{Bg} 30+\mathrm{Bg} 60] / 2+1 \times[\mathrm{Bg} 60+\mathrm{Bg} 120] / 2(\mathrm{Bg} 0$, Bg30, and Bg60 referred to the blood glucose concentration at $0,30,60$, and $120 \mathrm{~min}$ after glucose load).

\subsubsection{Insulin Tolerance Test (ITT) in Mice}

The ITT was performed as previously described. Briefly, mice deprived of $12 \mathrm{~h}$ were given TBE or metformin and injected Macrophage-CM as same as OGTT. Thirty minutes after the treatment, mice were injected with insulin (0.5 IU/kg, s.c.), and then, blood was collected from orbital sinus before and 30, 60 and $120 \mathrm{~min}$ after insulin injection. Glucose concentration was measured by glucose oxidase peroxidase method and the blood AUC was calculated same as a formula above in OGTT.

\subsubsection{Determination of Glycogen Content in Mice}

Glycogen contents of hepatic and muscle glycogen were measured by commercial kits based on anthrone reagent. Fasting mice for $12 \mathrm{~h}$, then given TBE or metformin (p.o.), injected Macrophage-CM (i.p.), and insulin (0.5 IU/kg, s.c) load as insulin tolerance test. After 30 min of insulin loading, mice was sacrificed by cervical dislocation, and liver and skeletal muscle tissues were treatment as the kit direction.

\subsubsection{Western Blot Analysis in Skeletal Muscle Tissue}

Mice were performed with TBE or metformin as mentioned earlier in the oral glucose tolerance test. After oral glucose load (30 min), mice were killed by cervical dislocation, and muscular tissue was chopped into small species and then homogenized in ice-cold cell lysis buffer $\left(1: 5, \quad \mathrm{wv}^{-1}, \mathrm{~g} \cdot \mathrm{mL}^{-1}\right)$ to extract the protein. The homogenates were incubated at $4^{\circ} \mathrm{C}$ for $30 \mathrm{~min}$ and then 
centrifuged at $12,000 \mathrm{rpm}$ at $4{ }^{\circ} \mathrm{C}$ for $15 \mathrm{~min}$ and supernatants were collected. The protein content of each sample was determined with Bicinchoninic Acid (BCA) Protein Assay kit (Biosky Biotechnology Corporation, Nanjing, China). Twenty to $40 \mu \mathrm{g}$ of protein were mixed with sample buffer, boiled for $10 \mathrm{~min}$. Equal amounts of protein samples (20-40 $\mu \mathrm{g})$ were separated by $10 \%$ SDSPAGE and transferred to PVDF membrane in a MiniTrans-Blot Electrophoretic Transfer Cell (Bio-Rad, USA). The PVDF membranes were blocked with 5\% skimmed milk in TBST buffer (Tris-HCl 5 mM, pH 7.6, $\mathrm{NaCl} 136 \mathrm{mM}, 0.05 \%$ Tween-20) for $2 \mathrm{~h}$ at room temperature or overnight at $4{ }^{\circ} \mathrm{C}$ and then incubated with primary antibody (1:800 dilution in TBST buffer) overnight at $4{ }^{\circ} \mathrm{C}$. Following washing three times with TBST buffer, the PVDF membranes were incubated with the secondary antibody to conjugate to HRP at room temperature for $2 \mathrm{~h}$. The intensity of signal was detected by the ECL and levels of protein expression were analyzed quantitatively using Quantity One software (Bio-Rad).

\subsection{Statistical Analysis}

All data were expressed as mean \pm S.D. for three or ten independent experiments. Statistical were analyzed by the
SPSS software (version 13). And differences were analyzed by one-way ANOVA and considered to be significant at the $P<0.05$ level.

\section{Results}

\subsection{TBE Reversed Glucose Intolerance in Mac-CM Treated Mice}

The oral glucose intolerance (OGTT) was firstly performed to investigate the effect of TBE at three different doses $(100,200$ and $500 \mathrm{mg} / \mathrm{kg}$ ) on glucose homeostasis under Mac-CM induced insulin-resistant conditions in mice. As shown in Figure 1a, the blood glucose level increased to the maximum at $30 \mathrm{~min}$ after glucose loaded, then gradually back to the basal level at 120 min. Administration of TBE p.o. at doses 200 and 500 $\mathrm{mg} / \mathrm{kg}$ markedly decreased blood glucose at 30 and 60 min by increasing blood glucose disposal, while not significantly change $(p>0.05)$ at dose of $100 \mathrm{mg} / \mathrm{kg}$. As indicated by the increase in AUC (Figure 1b). Metformin, as a positive agent, showed a positive regulation of glucose intolerance by increasing blood glucose disposal $(p<0.05)$.

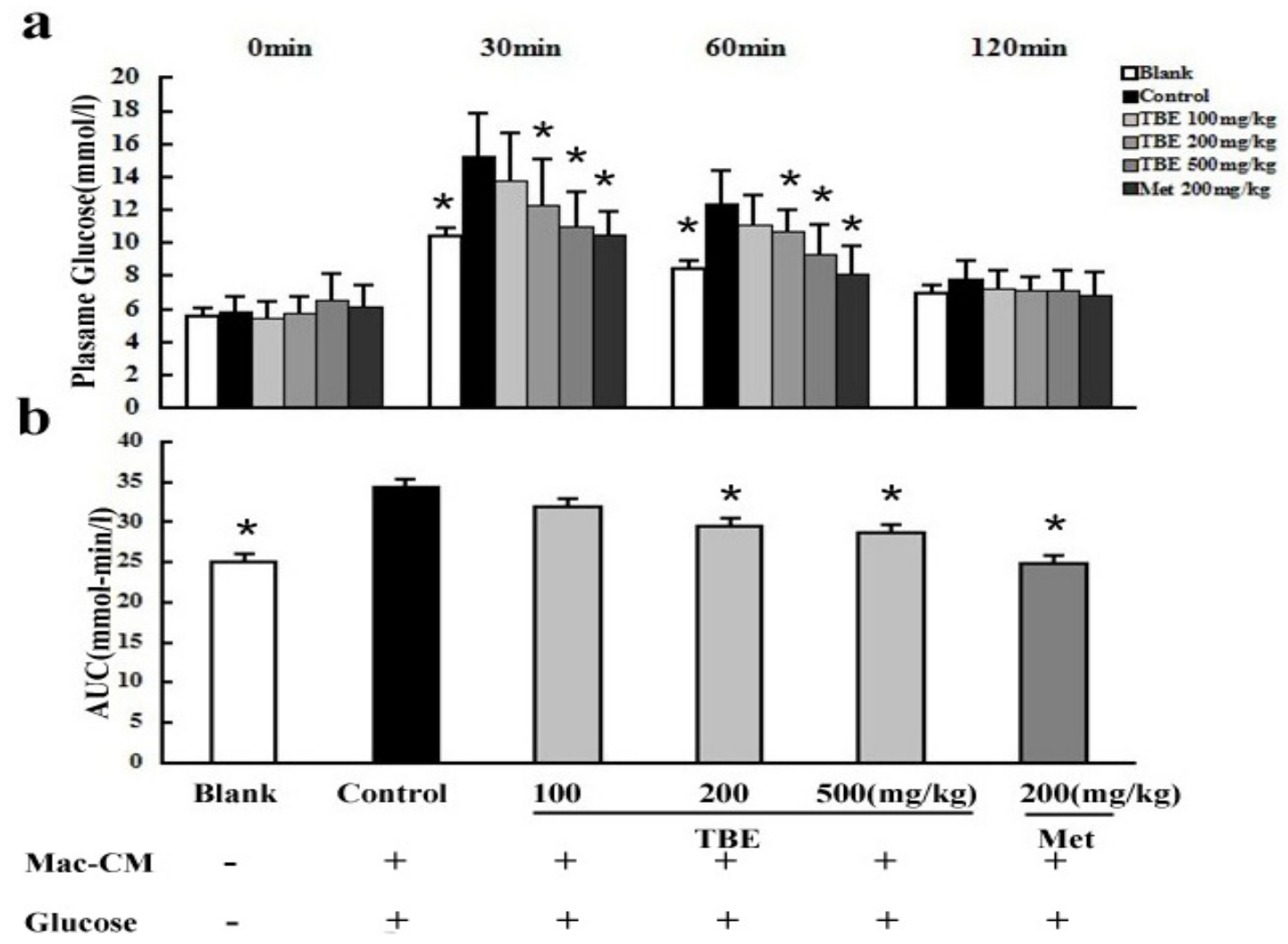

Figure 1. Oral glucose tolerance in mice under inflammation conditions. Mice were treated by gavage with TBE at concentrations of 100 , 200 and 500 $\mathrm{mg} / \mathrm{kg}$ or metformin (200 mg/kg). After $30 \mathrm{~min}$, mice were intraperitoneally injected with Mac-CM (0.1 mL/10g, diluted with saline, 1:1, v/v), and then mice were orally administered with glucose solution ( $2 \mathrm{~g} / \mathrm{kg}) 30 \mathrm{~min}$ later, and blood glucose was determined at given times. Metformin was taken as a positive control. The results were expressed as the mean $\pm \mathrm{SD}(\mathrm{n}=10)^{*} p<0.05$, compare to control

\subsection{TBE Ameliorated Insulin Intolerance in Mac-CM Treated Mice}

We further determined insulin intolerance in Mac-CM treatment impaired glucose tolerance in mice. Figure 2(a) showed that the blood glucose levels were sharply reduced after 30 min of insulin loaded. And Figure 2 (a and b) demonstrated that TBE treatment induced the improvement of insulin intolerance in Mac-CM treated mice. In the insulin intolerance test, the blood glucose levels were significantly low in TBE-treatment mice compared to Mac-CM treated group $(p<0.05)$. According to Figure 2(b), the change of blood glucose was not a dose-dependent manner in TBE-treated group. Metformin also demonstrated a similar modulation as the TBE enhancing insulin intolerance $(p<0.05)$. 
a

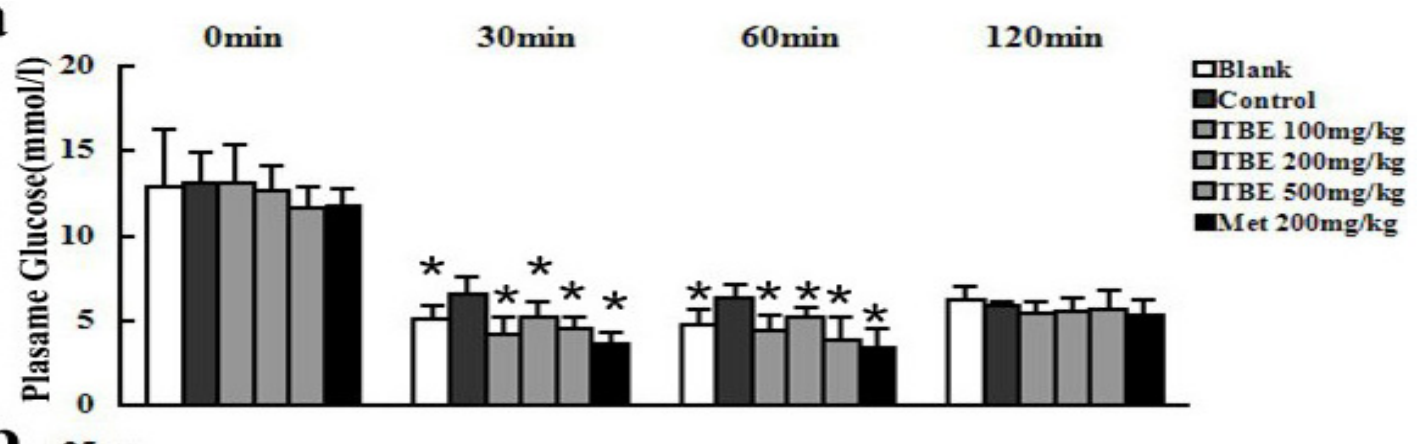

b

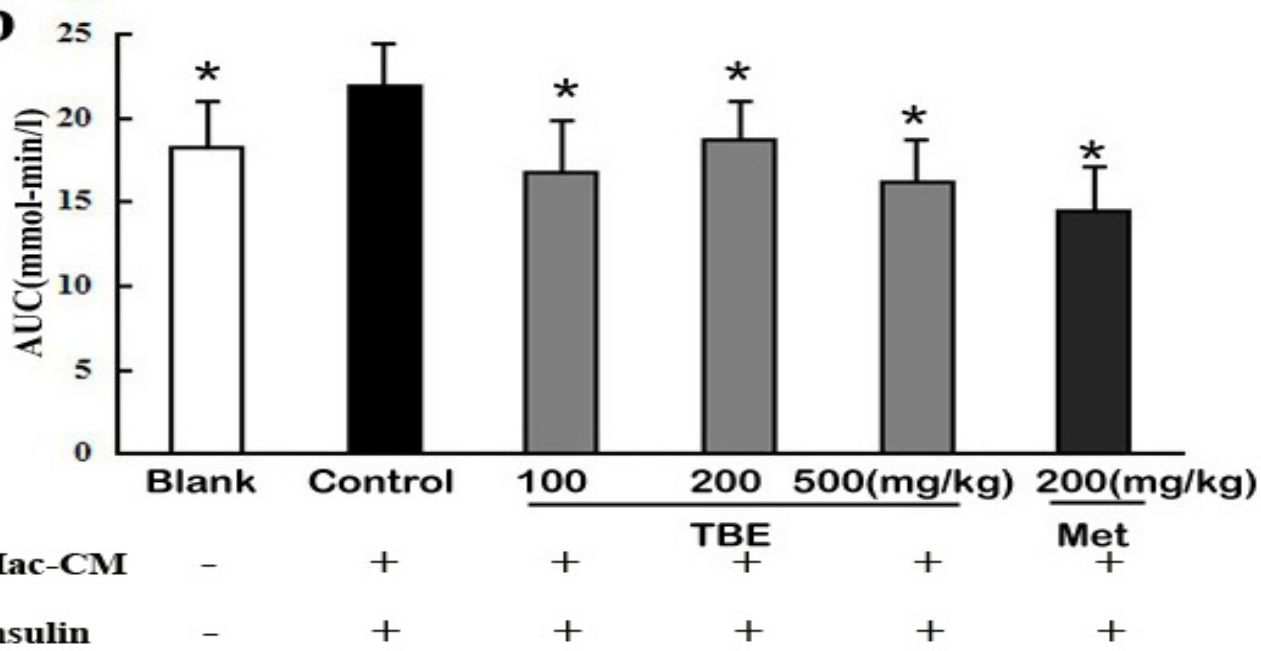

Figure 2. Insulin tolerance in mice under normal conditions. Mice were treated by gavage with TBE at concentrations of 100 , 200 and $500 \mathrm{mg} / \mathrm{kg}$ or metformin (200 mg/kg). After $30 \mathrm{~min}$, mice were intraperitoneally injected with Mac-CM (0.1 mL/10g, diluted with saline, 1:1, v/v). After $30 \mathrm{~min}$, mice were injected with insulin (0.5 IU/kg, s.c.), and blood glucose was determined at given times. Metformin was taken as a positive control. The results were expressed as the mean $\pm \mathrm{SD}(\mathrm{n}=10) .{ }^{*} \mathrm{p}<0.05$ compare to control
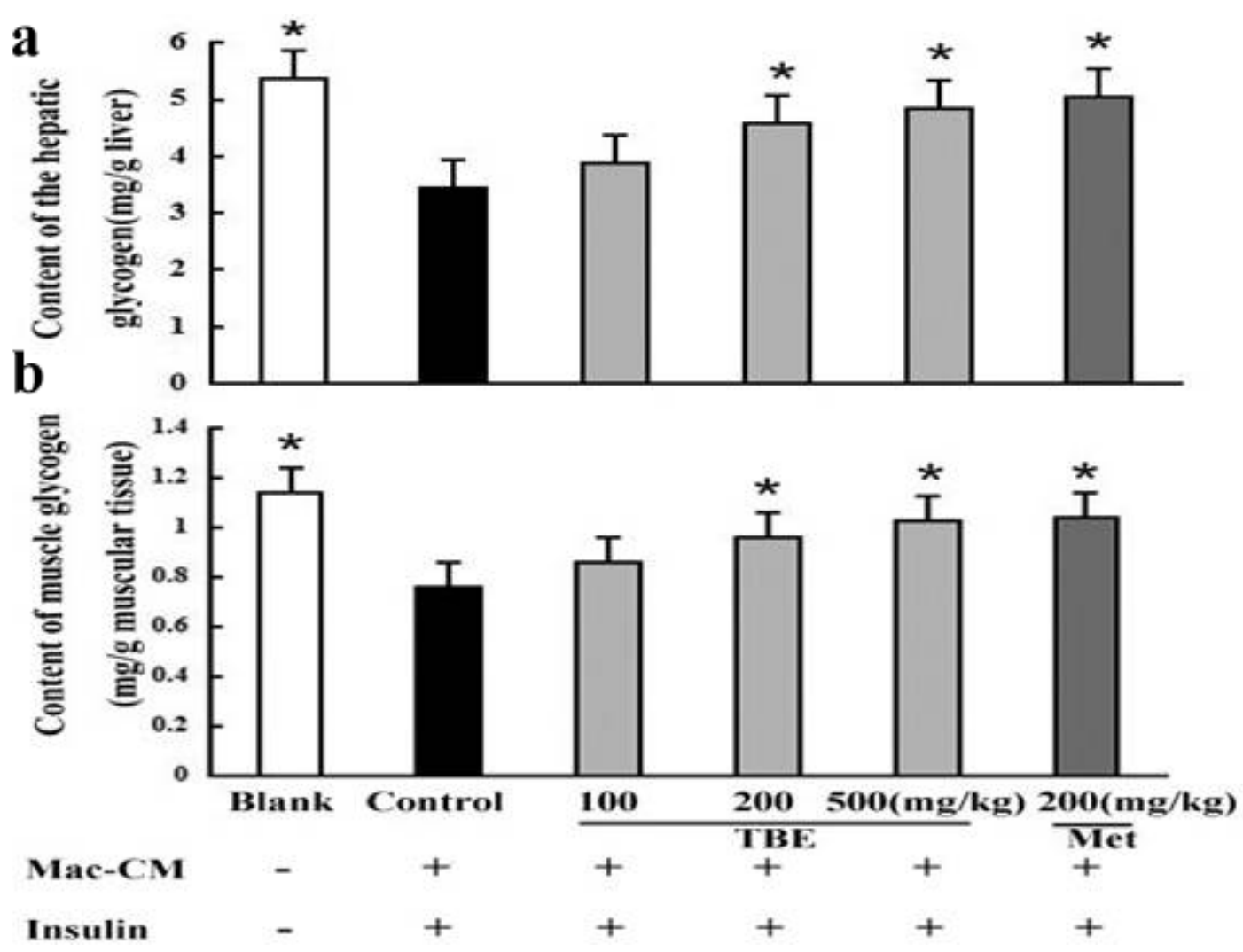

Figure 3. TBE enhanced insulin mediated glycogen synthesis of liver and skeletal muscle tissue in mice. Mice were treated by gavage with TBE at concentrations of 100, 200 and $500 \mathrm{mg} / \mathrm{kg}$ or metformin (200 mg/kg). After $30 \mathrm{~min}$, mice were intraperitoneally injected with Mac-CM (0.1 mL/10g, diluted with saline, $1: 1, \mathrm{v} / \mathrm{v})$. After $30 \mathrm{~min}$, mice were injected with insulin ( $0.5 \mathrm{IU} / \mathrm{kg}$, s.c.), and the hepatic and skeletal muscle glycogen were determined after $30 \mathrm{~min}$. Metformin was taken as a positive control. The results were expressed as the mean $\pm \mathrm{SD}\left(\mathrm{n}=10\right.$ ). ${ }^{*} \mathrm{p}<0.05$, compare to control 


\subsection{TBE Improved the Content of Muscular and Hepatic Glycogen in Mac-CM Treated Mice}

As shown in Figure 3(a), the content of hepatic glycogen was reduced in Mac-CM treated group compared to blank group after $30 \mathrm{~min}$ of insulin loaded. But this change was reversed by treatment with TBE. And the content of glycogen was significantly increased in medial-dose and high-dose of TBE groups $(p<0.05)$, slightly increased in low-dose group compared to control $(p>0.05)$. Meanwhile, there was a similar change trend on muscle glycogen. And the positive variation was demonstrated that TBE had an effect on modulating of glucose homoeostasis in Mac-CM induced mice.
Metformin also significantly restored muscular and hepatic glycogen evoked by Mac-CM $(p<0.05)$.

\subsection{TBE Inhibited Mac-CM-induced IKK $\beta$ Phosphorylation in Muscular Tissue}

Research has confirmed that IKK $\beta$ is a serine kinase related with inflammation and insulin resistance [20]. IKK $\beta$ phosphorylation was notablely increased in Mac$\mathrm{CM}$ treatment of mice, but this change was attenuated in TBE and metformin treatment groups (Figure 4). The result indicates that TBE was inhibited inflammatory response and enhanced insulin resistance in muscular tissue to some extent.

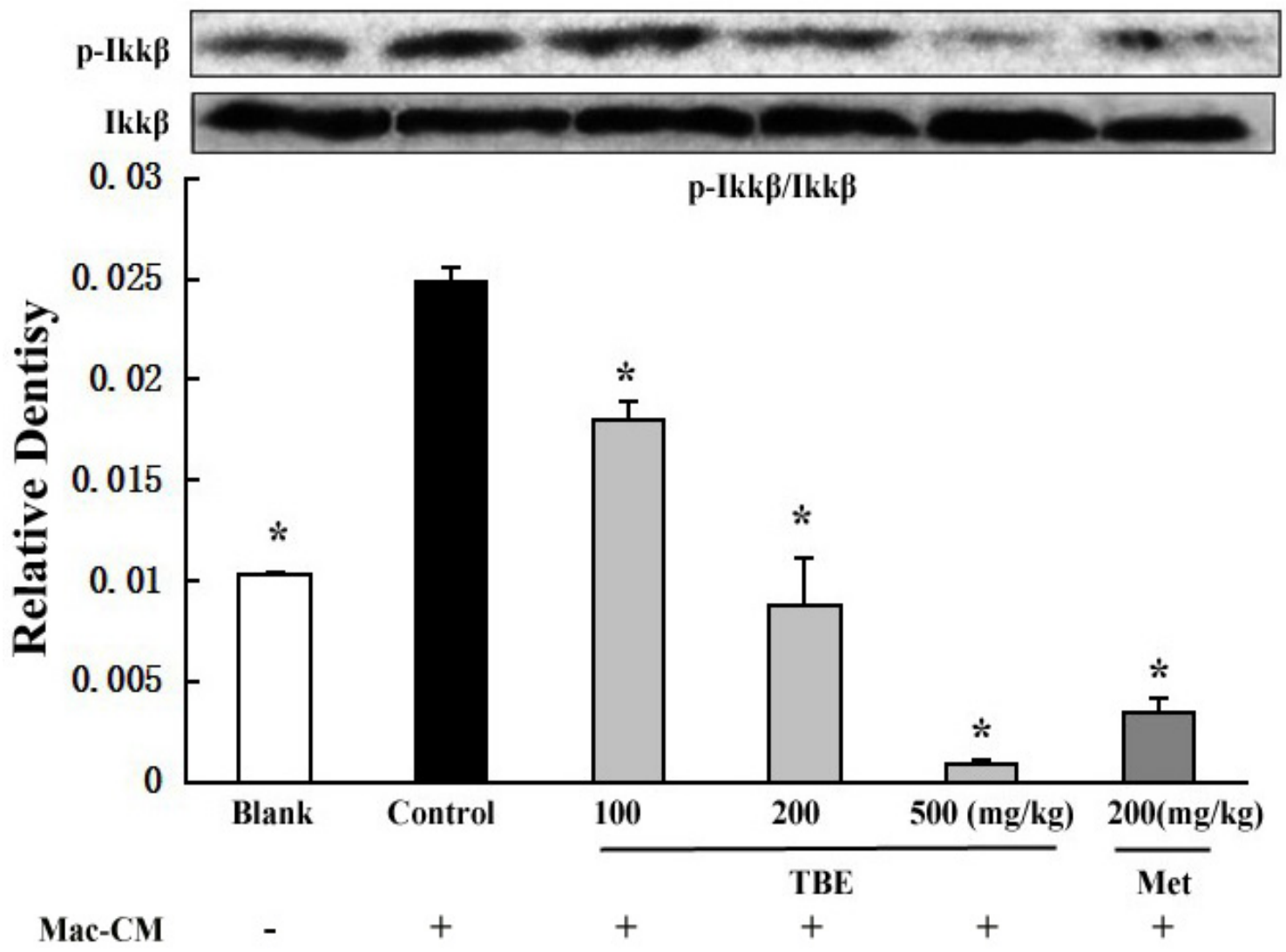

Figure 4. TBE inhibited the IKK $\beta$ phosphorylation in mice skeletal muscle tissue under insulin-resistant conditions. Mice were treated by gavage with TBE concentrations of 100, 200 and $500 \mathrm{mg} / \mathrm{kg}$ or metformin (200 mg/kg). After $30 \mathrm{~min}$, mice were intraperitoneally injected with Mac-CM (0.1 $\mathrm{mL} / 10 \mathrm{~g}$, diluted with saline, $1: 1, \mathrm{v} / \mathrm{v}$ ). For another $30 \mathrm{~min}$, muscle tissue was separated and homogenized for analyzing IKK $\beta$ phosphorylation by Western blot. Metformin was taken as a positive control. The results were expressed as the mean \pm S.D $(n=3)$. ${ }^{*} p<0.05$, compare to control

\subsection{TBE Modulated Serine/Tyrosine} Phosphorylation at IRS-1 in Mice of Muscular Tissue Exposed to Mac-CM

IRS-1 plays a crucial role in insulin signal pathway, which links inflammation to insulin resistance. Normally, insulin binds to the $\alpha$-subunit of insulin receptors to induce tyrosine autophosphorylation, then activating the downstream signaling pathway. We inspected the effect of TBE on modulation of IRS-1 serine/tyrosine phosphorylation in Mac-CM treatment of mice. Mac-CM treatment induced IRS-1 serine phosphorylation which disturbed the tyrosine phosphorylation normally. And in our study, TBE treatment group at $100 \mathrm{mg} / \mathrm{kg}$ failed to exert influence on IRS-1 serine/tyrosine phosphorylation, while the groups respectively at 200 and $500 \mathrm{mg} / \mathrm{kg}$ showed subsequently marked restored tyrosine phosphorylation. Metformin also showed similar positive influence on IRS-1 serine and tyrosine phosphorylation as TBE.

On the contrary of serine phosphorylation of IRS-1 by Mac-CM stimulation, tyrosine autophosphorylation was sharply restrained. But the alternation was reversed by treatment with TBE at 200 and $500 \mathrm{mg} / \mathrm{kg}$. It was well demonstrating TBE beneficial modulation of IRS-1 serine/tyrosine phosphorylation (Figure 5). Metformin also showed similar positive influence on IRS-1 serine and tyrosine phosphorylation as TBE. 


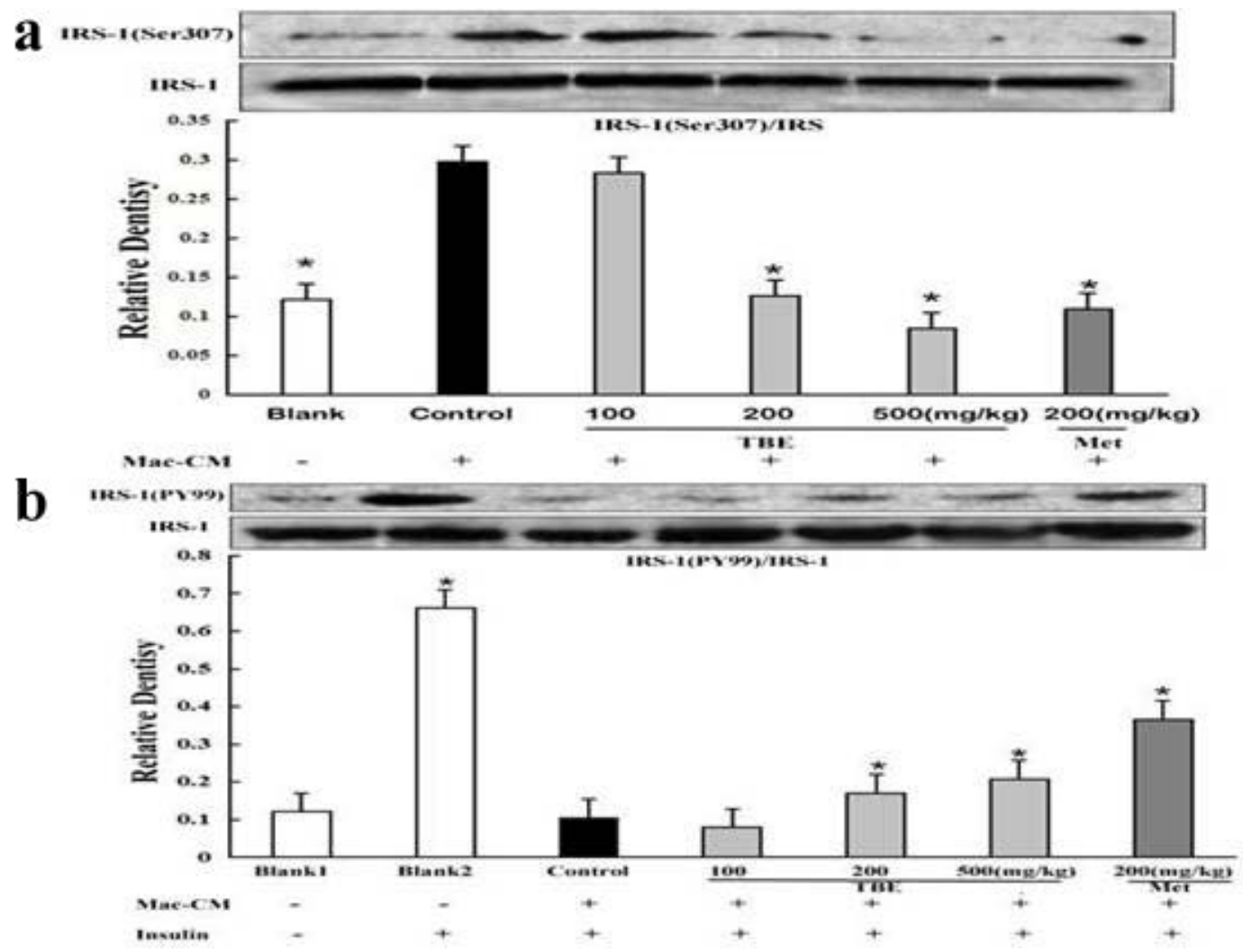

Figure 5. TBE regulated the IRS-1 serine/tyrosine phosphorylation in mice skeletal muscle tissue under insulin-resistant conditions. Mice were treated by gavage with TBE at concentrations of 100,200 and $500 \mathrm{mg} / \mathrm{kg}$ or metformin $(200 \mathrm{mg} / \mathrm{kg})$. After $30 \mathrm{~min}$, mice were intraperitoneally injected with Mac-CM $(0.1 \mathrm{~mL} / 10 \mathrm{~g}$, diluted with saline, 1:1, v/v). (a) For another $30 \mathrm{~min}$, muscle tissue was separated and homogenized for analyzing Serine (S307) phosphorylation of IRS-1 by Western blot. (b) For another 30 min, mice were injected with insulin (0.5 IU/kg, s.c.), and tyrosine (Py99) phosphorylation of IRS-1 was analyzed by Western blot after $30 \mathrm{~min}$. Metformin was taken as a positive control. The results were expressed as the mean $\pm \mathrm{SD}(\mathrm{n}=3) . * \mathrm{p}<0.05$, compare to control

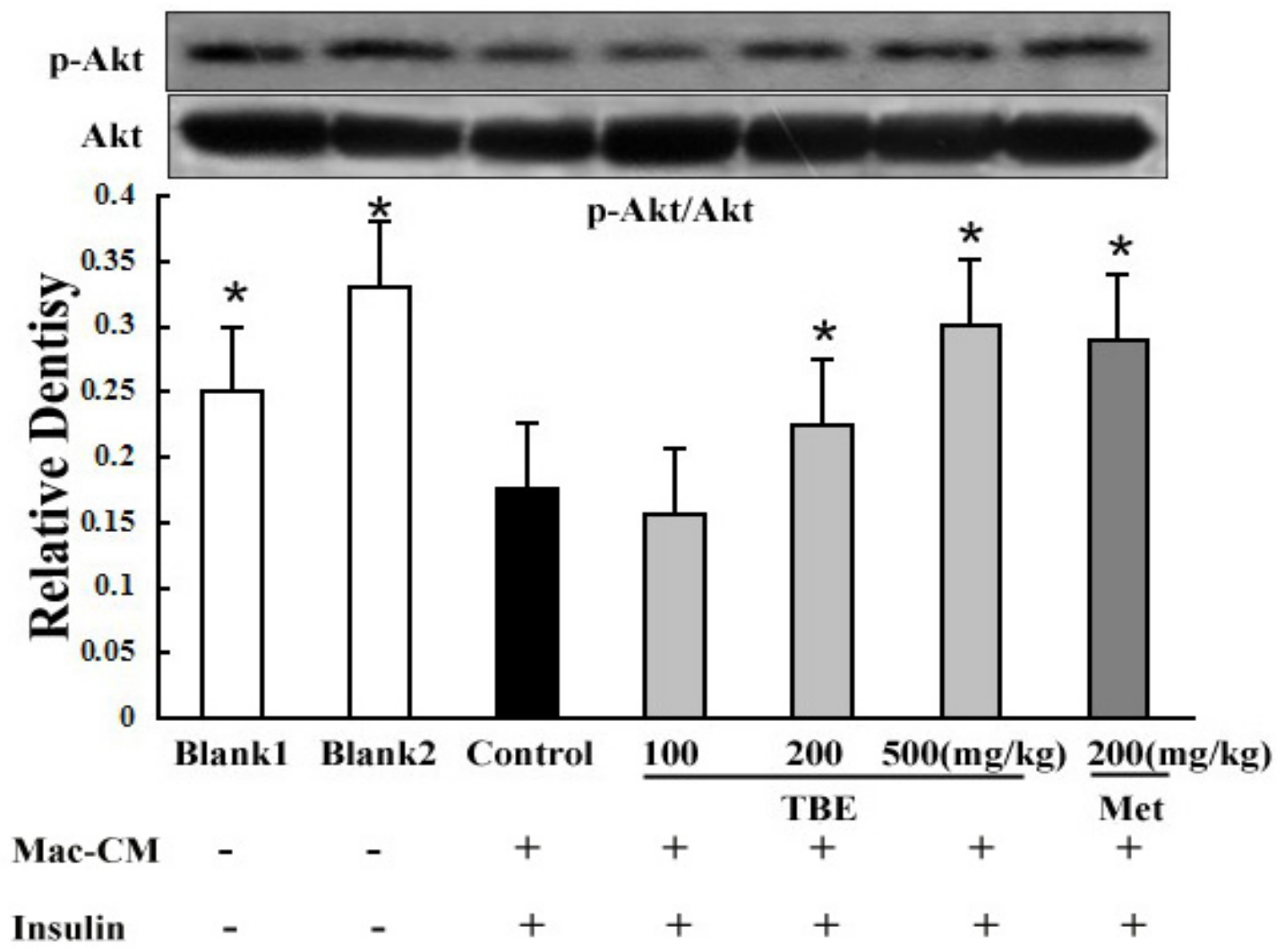

Figure 6. TBE enhanced the Akt phosphorylation in mice skeletal muscle tissue under insulin-resistant conditions. Mice were treated by gavage with TBE at concentrations of 100, 200 and $500 \mathrm{mg} / \mathrm{kg}$ or metformin $(200 \mathrm{mg} / \mathrm{kg})$. After $30 \mathrm{~min}$, mice were intraperitoneally injected with Mac-CM (0.1 $\mathrm{mL} / 10 \mathrm{~g}$, diluted with saline, $1: 1, \mathrm{v} / \mathrm{v})$ for another $30 \mathrm{~min}$. Mice were injected with insulin (0.5 IU/kg, s.c.). And Akt phosphorylation was detected by Western blot after $30 \mathrm{~min}$. Metformin was taken as a positive control. The results were expressed as the mean $\pm \operatorname{SD}\left(\mathrm{n}=3\right.$ ). ${ }^{*} p<0.05$, compare to control 


\subsection{TBE Restored Akt Phosphorylation in Mac-CM Treatment Mice}

As we all known, insulin modulating the glucose and lipid metabolism is mainly through IRS-1/PI3K/Akt signal pathway which is the classical pathway. Normally, Akt is activated by PI3-kinase, and then regulating downstream signaling pathways. So we further observed the effect of TBE on phosphorylations of Akt after insulin-load. MacCM treatment attenuated insulin-mediated Akt phosphorylation, but the inhibitory tendency was effectively reversed by TBE at 200 and $500 \mathrm{mg} / \mathrm{kg}$ (Figure 6). Metformin also restored Akt phosphorylation.

\section{Discussion}

Numerous data have demonstrated that flavonoids inhibit insulin-stimulated glucose uptake in muscle cell, liver and adipose tissues [21,22]. Cazarolli et al. [23] reported that flavonoids ameliorated diabetes mellitus by regulation pleiotropic mechanisms of insulin signaling, such as stimulating glucose uptake in peripheral tissue, regulating the activity or expression of the rate-limiting enzymes in carbohyotropic metabolism and modulating insulin secretion or insulin analog. It has recently been reported that flavonoid-rich extract from seeds of Eugenia jambolana (L.) significantly improves glucose tolerance, lipid profile, glycogen biosynthesis, glucose uptake and insulin release in vivo and vitro on streptozotocin-induced diabetic mice [24]. It is known that tartary buckwheat can prevent cardiovascular disease and type 2 diabetes mellitus in favour of abundant flavonoids, especially rutin. In the present study, we observed the effect of TBE on regulation of insulin action in Mac-CM induced mice, and found TBE could exert positive influence on glucose level by acting on IKK $\beta /$ IR/IRS-1/PI3K/Akt pathway.

To known whether TBE regulates insulin action in vivo through the classical pathway, IKK $\beta /$ IR/IRS-1/PI3K/Akt signaling cascade, we firstly observed the influence of TBE on glucose tolerance in insulin-resistant mice induced by Mac-CM. Glucose load stimulates insulin secretion from pancreatic islets, and insulin in turn promotes glucose disposal [25]. Administration of TBE significantly restored blood glucose level in OGTT and ITT. These results suggested that TBE had a positive effect on glucose homeostasis mice by regulating insulin sensitivity under insulin-resistance conditions in skeletal muscle tissue. Similar results were demonstrated by the previous research that flavonoid-rich extracts are beneficial to maintain glucose homeostasis in vivo [24,26,27,28,29].

Glycogen exists extensively in bodies and deposits the redundant blood glucose to keep extracellular glucose concentration [30], especially in liver and skeletal muscle tissue. And the levels of hepatic and muscle glycogen are tightly linked with insulin action and directly reflect the activity of insulin. Researches have found that the glycogen levels in skeletal muscle and liver decreased due to the absence of insulin [31], which activates glucose transport, glucose uptake and metabolism and glycogen synthesis to maintain glucose homeostasis. To further verify the effect of $\mathrm{TBE}$ on glucose homeostasis, we determined the levels of hepatic and muscle glycogen in insulin resistance mice. In the present study, mice were stimulated with Macrophage-CM to impair insulin signaling, and the concentration of hepatic and muscle glycogen in response to insulin was recuperated by TBE. This result was also consistent with the earlier data, which showed the administration of crude extracts of EJ (Eugenia jambolana) plant improved the hepatic and skeletal muscles glycogen contents levels as compared to control [32]. The increasing of glycogen content might be the flavonoids playing a role in regulating hepatic hexokinase and glucose-6 phosphatase enzyme which tightly linked with insulin signal pathway.

Growing evidence had established that inflammation is closely associated with skeletal muscle insulin resistance [33]. And IKK $\beta / \mathrm{NF}-\kappa \mathrm{B}$ axis is identified as a classical inflammatory pathway that associated inflammation with insulin resistance [34]. As a serine/threonine protein kinase, IKK $\beta$ activates NF- $\kappa \mathrm{B}$ through transcriptional regulation in involvement of inflammatory pathways. Then NF- $\mathrm{KB}$ stimulates the production of numerous markers and potential mediators of inflammation, including TNF-a and IL-6, causing insulin resistance [34, 35]. In return, pro-inflammatory cytokines activate the IKK $\beta / \mathrm{I} \kappa \mathrm{B} / \mathrm{NF}-\kappa \mathrm{B}$ inflammatory pathway that results a vicious circle leading to insulin resistance. MacrophageCM contained inflammatory mediators including TNF- $\alpha$ and IL-6, which was derived from activated macrophages [36]. Studies have proved that TNF- $\alpha$ and IL-6 are the pivotal cytokines tempting serine phosphorylation instead of blunting tyrosine autophosphorylation of IRS-1 in response to insulin induced the inflammation in muscle tissue. Obviously, insulin resistance induced by Macrophage-CM is characteristic of inflammation evidenced by IKK $\beta$ activation [36]. As Schenk et al. [37] said, inactivation of IKK $\beta / \mathrm{NF}-\kappa \mathrm{B}$ pathway can control lipid-induced insulin resistance and decrease the proinflammatory stress in skeletal muscle to alleviate insulin resistance. Thus, the pivotal target is to prevent IKK $\beta$ phosphorylation to control inflammatory and improve insulin resistance. In this study, the TBE greatly diminished IKK $\beta$ phosphorylation under Macrophage-CM induced insulin resistance with (Figure 4), well demonstrating that TBE could blocked the inflammatory cross-talk between macrophages and skeletal muscle tissue.

Many studies have suggested that the serine phosphorylation of IRS-1 is a link between inflammation and insulin resistance, and provide negative feedback to insulin signaling to attenuate insulin-stimulated tyrosine phosphorylation [37]. Meanwhile, serine phosphorylation of IRS-1 can be activated by serine/threonine kinase, inducing insulin resistance. Therefore, keeping the normal phosphorylation of IRS-1 is the key to inhibit insulin resistance and maintain the glucose homeostasis. Thus, we examined the effect of TBE on the phosphorylation of IRS-1 subunits under inflammation condition. Macrophage-CM stimulation induced serine phosphorylation and blunted tyrosine phosphorylation of IRS-1 in respond to glucose load, and these changes were restored by TBE (Figure 5). These results confirmed that inflammation was involved in the impairment of IRS-1 function and TBE played a positive role in IRS-1 function by modification of serine/tyrosine phosphorylation of IRS- 
1, leading to improvement of PI3K signaling evidenced by restored Akt phosphorylation(Figure 6). Accordance with the early published reports [38,39,40,41], the tyrosine phosphorylation of IRS-1 activates phosphorylation of downstream signaling events, including Akt, in skeletal muscle. In addition, Shao et al. [36] found that flavonoids ameliorated Akt phosphorylation by modulating IRS-1 phosphorylation rather than PI3-Kinase activity under inflammatory conditions. So, we can deduce that TBE improved the Akt phosphorylation which was the result of regulation of upstream protein molecular phosphorylation of IR/IRS-1/PI3K pathway. What's more, flavonoids, as multifunctional natural active substance, might also be possible to regulate insulin action in an insulinindependent pathway. Therefore, more studies need to be carried out to clarify the key functional agent and target molecule.

In conclusions, our study indicated that TBE absorption by insulin-resistance mice regulated glucose homeostasis, such as glycemic level and the content of glycogen, via ameliorating insulin sensitivity. Significantly, TBE improved insulin action by blocking IKK $\beta$ activation and effectively propagating insulin signaling transduction along IRS-1/Akt pathway (Figure 7). Therefore, TBE can prevent the development of insulin resistance to some extent.

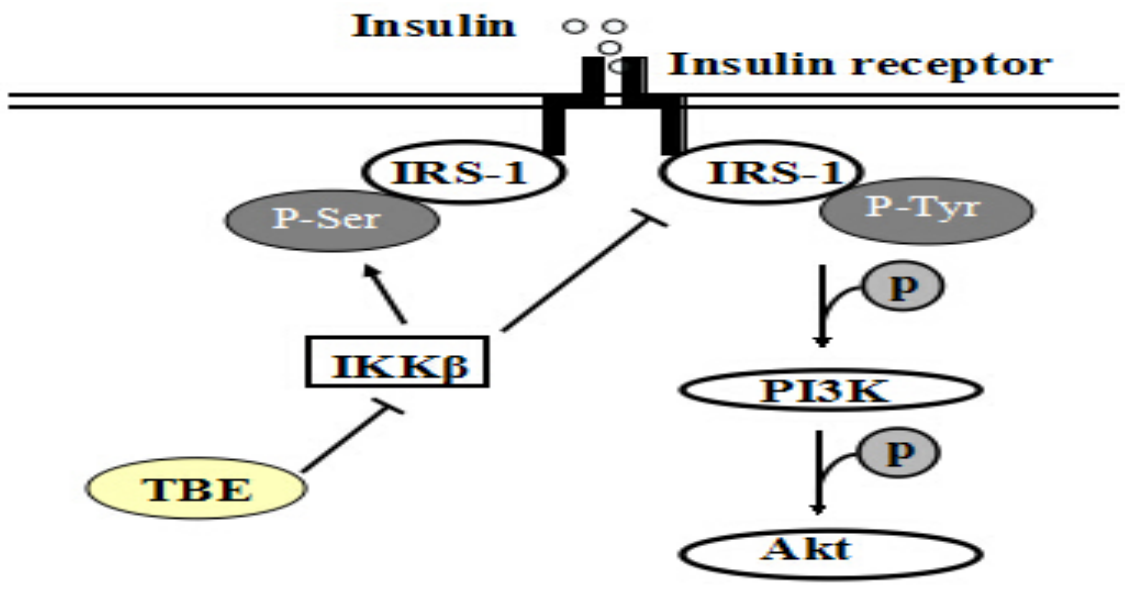

Figure 7. Proposed action pathway of TBE to regulate insulin IRS1/Akt signalling in insulin resistance mice. Under inflammatory conditions, TBE inhibited insulin tyrosine phosphorylation of IRS-1 via suppressed IKK $\beta$ phosphorylation, restoring transduction of the insulin IRS-1/Akt pathway

\section{Acknowledgement}

This work was fund by the earmarked fund for China Agriculture Research System (CARS-08-D-2), and National Key Technology R \& D Program (2012BAD34B05), People’s Republic of China.

\section{References}

[1] Zygmunt, K., Faubert, B., MacNeil, J., Tsiani, E. 2010. Naringenin, a citrus flavonoid, increases muscle cell glucose uptake via AMPK. Biochem Biophys Res. 398, 178-183.

[2] Breen, D.M., Sanli, T., Giacca, A., Tsiani, E. 2008. Stimulation of muscle cell glucose uptake by resveratrol through sirtuins and AMPK. Biochem Biophys Res Commun. 374, 117-122.

[3] Gual, P., Le Marchand-Brustel Y., Tanti, J.F. 2005. Positive and negative regulation of insulin signaling through IRS-1 phosphorylation. Biochimie. 87, 99-109.

[4] Shoelson, S.E., Lee, J., Goldfine, A.B. 2006. Inflammation and insulin resistance. J Clin Invest. 116, 1793-1801.

[5] Guo, X.D., Zhang, D.Y., Gao, X.J., Parry, J., Liu, K., Liu, B.L., Wang, M. 2013. Quercetin and quercetin-3-0-glucuronide are equally effective in ameliorating endothelial insulin resistance through inhibition of reactive oxygen species-associated inflammation. Mol Nutr Food Res. 57, 1037-1045.

[6] Arkan, M.C., Hevener, A.L., Greten, F.R., Maeda, S., Li, Z.W., Long, J.M., Wynshaw-Boris, A., Poli, G., Olefsky, J., Karin, M. 2005. IKK- $\beta$ links inflammation to obesity-induced insulin resistance. Nat Med. 11, 191-198.

[7] Manthey, J.A., 2000. Biological properties of flavonoids pertaining to inflammation. Microcirculation. 7, S29-S34.

[8] Gonzalez, R., Ballester, I., Lopez-Posadas, R., Suarez, M.D., Zarzuelo, A., Martinez-Augustin, O., Medina, F.S.D. 2011.
Effects of flavonoids and other polyphenols on inflammation. Crit Rev Food Sci Nutr. 51, 331-362.

[9] García-Lafuente, A., Guillamón, E., Villares, A., Rostagno, M.A., Martínez, J.A. 2009. Flavonoids as anti-inflammatory agents: implications in cancer and cardiovascular disease. Inflamm Res. 58, 537-552.

[10] Guo, X.D., Ma, Y.J., Parry, J., Gao, J.M., Yu, L.L., Wang, M. 2011. Phenolics content and antioxidant activity of tartary buckwheat from different locations. Molecules. 16, 9850-9867.

[11] Fabjan, N., Rode, J., Košir, I.J., Wang, Z., Zhang, Z., Kreft, I. 2003. Tartary buckwheat (Fagopyrum tataricum Gaertn.) as a source of dietary rutin and quercitrin. J Agric Food Chem. 51, 6452-6455.

[12] Zielinski, H., Kozlowska, H. 2000. Antioxidant activity and total phenolics in selected cereal grains and their different morphological fractions. J Agric Food Chem. 48, 2008-2016.

[13] Li, D., Xiao, G., Ding, X. 2000. Study on the free radical scavenging effects of tartary buckwheat flavone. Food Sci Technol. 6, 62-64.

[14] Pinent, M., Castell, A., Baiges, I., Montagut, G., Arola, L., Ardevol, A. 2008. Bioactivity of flavonoids on insulin-secreting cells. Compr Rev Food Sci F. 7, 299-308.

[15] Jiang, P., Burczynski, F., Campbell, C., Pierce, G., Austria, J.A., Briggs, C.J. 2007. Rutin and flavonoid contents in three buckwheat species Fagopyrum esculentum, F. tataricum, and F. homotropicum and their protective effects against lipid peroxidation. Food Res Int. 40, 356-364.

[16] Lee, C.C., Hsu, W.H., Shen, S.R., Cheng, Y.H., Wu, S.C. 2012. Fagopyrum tataricum (buckwheat) improved high-glucoseinduced insulin resistance in mouse hepatocytes and diabetes in fructose-rich diet-induced mice. Exp Diabetes Res. 2012, 1-10.

[17] Gong, F.Y., Li, F.L., Zhang, W.M., Li, J., Zhang, Z. 2012. Effects of crude flavonoids from tatary buckwheat on alloxan-induced oxidative stress in mice. Bangl J Pharmacol. 7, 124-130.

[18] Lee, C.C., Shen, S.R., Lai, Y.J., Wu, S.C. 2013. Rutin and quercetin, bioactive compounds from tartary buckwheat, prevent liver inflammatory injury. Food Funct. 4, 794-802.

[19] Liu, K., Luo, T.J., Zhang, Z.A., Wang, T., Kou, J.P., Liu, B.L., Huang, F. 2011. Modified Si-Miao-San extract inhibits 
inflammatory response and modulates insulin sensitivity in hepatocytes through an IKK $\beta$ /IRS-1/Akt-dependent pathway. J Ethnopharmacol. 136, 473-479.

[20] Kim, F., Tysseling, K.A., Rice, J., Pham, M., Haji, L., Gallis, B.M., Baas, A.S., Paramsothy, P., Giachelli, C.M., Corson, M.A. Raines, E.W. 2005. Free fatty acid impairment of nitric oxide production in endothelial cells is mediated by IKK $\beta$. Arterioscler Thromb Vasc Biol. 25, 989-994.

[21] Zygmunt, K., Faubert, B., MacNeil, J., Tsiani, E. 2010. Naringenin, a citrus flavonoid, increases muscle cell glucose uptake via AMPK. Biochem Biophys Res Commun. 398(2), 178183.

[22] Breen, D.M., Sanli, T., Giacca, A., Tsiani, E. 2008. Stimulation of muscle cell glucose uptake by resveratrol through sirtuins and AMPK. Biochem Biophys Res Commun. 374, 117-122.

[23] Cazarolli, L.H., Zanatta, L., Alberton, E.H., Reis, B.F., Maria, S., Folador, P., Damazio, R.G., Pizzolatti, M.G., Mena, B.S., Fatima, R. 2008. Flavonoids: Cellular and Molecular Mechanism of Action in Glucose Homeostasis. Mini Rev Med Chem. 8, 10321038.

[24] Sharma, B., Viswanath, G., Salunke, R., Roy, P. 2008. Effects of flavonoid-rich extract from seeds of Eugenia jambolana (L.) on carbohydrate and lipid metabolism in diabetic mice. Food Chem. 110, 697-705.

[25] Wang, M., Gao, X.J., Zhao, W.W., Zhao, W.J., Jiang, C., Huang, F., Kou, J.P., Liu, B.L., Liu, K. 2013. Opposite effects of genistein on the regulation of insulin-mediated glucose homeostasis in adipose tissue. Brit J Pharmaco. 170, 328-340.

[26] Jorge, A.P., Horst, H., Sousa, E.D., Pizzolatti, M.G., Silva, F.R.M.B. 2004. Insulinomimetic effects of kaempferitrin on glycaemia and on 14C-glucose uptake in rat soleus muscle. ChemBiol Interact. 149, 89-96.

[27] Mulvihill, E.E., Assini, J.M., Lee, J.K., Allister, E.M., Sutherland, B.G., Koppes, J.B., Sawyez, C.G., Edwards, J.Y., Telford, D.E., Charbonneau, A., St-Pierre, P., Marette, A., Huff, M.W. 2011. Nobiletin attenuates VLDL overproduction, dyslipidemia, and atherosclerosis in mice with diet-induced insulin resistance. Diabetes. 60, 1446-1457.

[28] Achrekar, S., Kaklij, G.S., Pote, M.S., Kelkar, S.M. 1991. Hypoglycemic activity of Eugenia jambolana and Ficus bengalensis: mechanism of action. In Vivo. 5, 143.
[29] Sharma, S.B., Nasir, A, Prabhu, K.M., Murthy, P.S. 2006. Antihyperglycemic effect of the fruit-pulp of Eugenia jambolana in experimental diabetes mellitus. J Ethnopharmacol. 104, 367373

[30] Beck-Nielsen, H., Vaag, A., Damsbo, P., Handberg, A., Nielsen, O.H., Henriksen, J.E., Thye-Rønn, P. 1992. Insulin resistance in skeletal muscles in patients with NIDDM. Diabetes Care. 15, 418429.

[31] Golden, S., Wals, P.A., Okakima, F. 1979. Glycogen synthesis by hepatocytes from diabetic rats. Biochem J. 182, 727-734.

[32] Sharma, B., Balomajumder, C., Roy, P. 2008. Hypoglycemic and hypolipidemic effects of flavonoid rich extract from Eugenia jambolana seeds on streptozotocin induced diabetic rats. Food Chem Toxicol. 46, 2376-2383.

[33] Wei, Y., Chen, K., Whaley-Connell, A.T., Stump, C.S., Ibdah, J.A., Sowers, J.R. 2008. Skeletal muscle insulin resistance: role of inflammatory cytokines and reactive oxygen species. Am J Physiol Regul Integr Comp Physiol. 294, 673-680.

[34] Shoelson, S.E., Lee, J., Goldfine, A.B. 2006. Inflammation and insulin resistance. J Clin Invest. 116, 1793-1801.

[35] Shoelson, S.E., Lee, J., Yuan, M. 2003. Inflammation and the $\mathrm{IKK} \beta / \mathrm{I} \kappa \mathrm{B} / \mathrm{NF}-\kappa \mathrm{B}$ axis in obesity-and diet-induced insulin resistance. Int J Obesity. 27, S49-S52.

[36] Shao, L., Liu, K., Huang, F., Guo, X.D., Wang, M., Liu, B.L. 2013. Opposite Effects of Quercetin, Luteolin, and Epigallocatechin Gallate on Insulin Sensitivity Under Normal and Inflammatory Conditions in Mice. Inflammation. 36, 1-14.

[37] Schenk, S., Horowitz, J.F. 2007. Acute exercise increases triglyceride synthesis in skeletal muscle and prevents fatty acidinduced insulin resistance. J Clin Invest. 117(6), 1690-1698.

[38] Taha, C., Klip, A. 1999. The insulin signaling pathway. J Membrane Biol. 169, 1-12.

[39] Chang, L., Chiang, S.H., Saltiel, A.R. 2004. Insulin signaling and the regulation of glucose transport. Mol Med. 10, 65-71.

[40] Krook, A., Wallberg-Henriksson, H., Zierath, J.R. 2004. Sending the signal: molecular mechanisms regulating glucose uptake. Med Sci Sports Exerc. 36, 1212-1217.

[41] Kanzaki, M. 2006. Insulin receptor signals regulating GLUT4 translocation and actin dynamics. Endocr J. 53, 267-293. 